\title{
Directions and problems of research of modern industrial cities in Uzbekistan
}

\author{
Haydarov Dilshod Ochilovich ${ }^{1}$ \\ ${ }^{1}$ Base doctorate, Samarkand State University, Uzbekistan \\ Email:dilshod.xaydarov.1987@mail.ru
}

\begin{abstract}
This paper makes analyses of the directions and problems of the research of modern industrial cities. Evidences of Uzbek cities were given in the example of the Central Asia. On this case, lifestyle of the people with major point were directed research topic. Also, possible point to observe a further research directions to increase in the role and status of cities as an economic and Cultural Center were investigated and pointed out for the further developments.
\end{abstract}

Keywords: Directions, problems, research, cities, lifestyle, Uzbekistan.

\section{INTRODUCTION}

By the beginning of the XXI century, it is possible to observe a further increase in the role and status of cities as an economic and Cultural Center. According to some data, 600 large urban centers around the world are developing 60 percent of the world's gross domestic product. By 2025 year, it is estimated that about a quarter of the population of the Earth will live in these cities, as well as almost 600 "middle cities", which are developing at a high pace in the above-mentioned urban system, will be added in the near future . According to other summaries, the population of cities of countries in the state of transition from 2000 to 2030 years is from 2 to 4 mlrd.ga, their area is three-fold growth (that is, from 200 to 600 thousand sq.to KM) expected. The point is that while the states in the North, which had developed mainly until the beginning of the XXI century, were leaders in urbanization processes, in the new millennium, the plague of urban development is moving to the South, more precisely to the developing Eastern countries.

In fact, in the countries of Central Asia, which are experiencing a period of transit, in particular, Uzbekistan, there are also the basics of this process. From history it is known that the region is a developed region with a city culture of several thousand years. From the early days when the Great Silk Road was founded, Samarkand, Bukhara, Khiva, Termez, like other cities of the region, became the Centers of intercontinental trade, interaction and interrelationship of world civilizations. From the end of the XIX century until now, transformations under the influence of historical processes have changed the economic, cultural and social environment of cities, which seriously (both positively and negatively) affected the urbanization processes in the territory of modern Uzbekistan. In the years of independence, the development of Republican cities was not smoothed out due to the difficulties and problems of the transition period. The lack of investment has led to the contradictory course of urbanization during the Czech reform period, especially in 1991-2016 years. It is possible to observe that from 2017 Year, bold steps have been taken to solve the problems that have accumulated in the infrastructure of cities, to revive their economic development. Taking into account the comments, we touched on the features of studying the problem of cities, the process of urbanization in the article.

\section{THEORITICL BACKGROUND}

The modern stage of development of historical science in Uzbekistan requires the broad use of the method of science. Especially this situation concerns all aspects of the new and most recent history. On the one hand, if the method of science helps to comprehensively study the unexplored aspects of modern history, aspects of which are not known to many, on the other hand, it allows to study the history of Uzbekistan in harmony with the world or regional processes.

Since the second half of the XIX century, the period dictates the necessity of studies aimed at studying the socio-economic processes of the beginning of the XXI century, including the history of cities, primarily on the basis of a combination of different sciences (history, economy, sociology, political science, geography, demography and other sciences). In the history of mankind, exactly the same time interval is 
considered the period when the new industrial society reached its peak, and in the civilized states from the second half of the twentieth century the transition to postindustrial society began. The transition to industrial society began later in Uzbekistan, where the ranks of developing countries took place. Taking into account this, it is possible to analyze in depth and comprehensively the historical processes that occurred during this period, including economic and social transformations in the cities of the Republic.

One of the pressing issues that requires a fanatical approach is the history of these cities, in particular the history of the formation and development of industrial cities. Existing literature shows that this topic is being studied mainly by geographers, economists and historians.

It should be noted that several scientific studies created by historian scientists on the topic of cities, firstly, did not specifically study the topic of industrial cities as an object of research, and secondly, the spirit of a narrative approach in them prevailed and was not analyzed on the basis of a combination of different sciences. The researchers covered the history of cities on the basis of empirical generalizations, historical facts. This research is mainly reflected in the positive experiences accumulated during a short historical period. According to lead in this respect, according to the work recorded in most cases does not meet the modern requirements.

Taking the above into account, it is necessary to dwell on the theoretical aspects of a number of issues related to the methods of research, proceeding from the goals and objectives set in our study, the object and the subject.

In the current system of modern sciences, it occupies a place in the study of direct population and population punk (in particular, cities) and related issues in the modern economic and social geography and in the field of Geourbanistics formed on their basis. Therefore, it is natural that theoretical insight and attitudes within this science will serve as a methodological basis for the study.

\section{MAIN PART}

In the scientific literature and research, one can see that the interpretation of the concept of the city is diverse and does not come to a unanimous stop on this, despite the fact that cities are widespread and the concept of "city" has become customary, there is no universally accepted criterion that perfectly describes this concept in the world. Taking into account this, we consider that the definition given in the dictionary "socio-economic geography: concepts and terms", compiled by geographer and economist specialists, from modern requirements, is optimal. In it, it is noted that the city-by-Country legislation is spoken in relation to the population punk, which belongs to the category of cities, which has the legal status of the city*.

As a rule, cities (compared to rural population punks) are characterized by a large number of population and density, as well as employment in non-agrarian areas of the population, type of accommodation devices (mostly multi-storey buildings), lifestyle. As a common criterion, the population is accepted (the minimum limit of the population is from 1 to 2,5 thousand people).

An important role was played by the method of comparative analysis, which was considered one of the fundamental methods of knowledge in the study of the subject of cities, including in the framework of socio-humanitarian Sciences, which is also common in the science of geography. The reason is that the method of experimentation in their research in the scope of the stated subjects is extremely limited. Taking this into account, in the study of the history of the period of independence of the cities of the Zarafshan economic district, we tried to study the indicators of the territory in comparison with the world experience of other districts, depending on the scale and necessity of the Republic.

One of the common methods in geoorbanistics is the typological method. Typology is a method of studying complex objects by determining their basic properties. In the study of cities, the method of urban typology is important, since the typology of cities makes it possible to determine the location of any city among other cities. Well, the city type is a classification in a short, extremely condensed form, a selfcontained formula. Because, the city is a mixture of the situation and individual aspects inherent in all as an object .

The method of classification of cities is the debacle (threshold) of this typology. Because the city classification takes into account only one sign (for example, the number of inhabitants), and typology the distribution of cities by type - relies on the combination of signs. In other words, it is the highest stage of classification .

Several types of urban typology have been developed and used in practice in geoorbanistics. The point is that urban typology is not a social geography, it is mainly developed from the point of view of economic geography that is important to our research. They consist of: genetic typology; functional typology consisting of several sections; synthetic (integral) functional typology of cities. In particular, among these were considered close to the territorial direction of our study - the economic geo - location (IgJ) as a

\footnotetext{
* Социально-экономическая география: понятия и термины. Словарь-справочник / под ред. А. П. Горкина. - Смоленск: Ойкумена, 2013. С. 73.
} 
typological character-the functional type performed as a methodological guide in the analysis of Zarafshan economic District cities.

Modern cities, depending on their functional functions, are divided into multifunctional political and administrative centers (regional centers and capital cities), diversified large industrial centers, cities specializing in several or one industrial network, transport and logistics centers; agroindustrial cities, recreation cities, science centers, unversitet cities .

In general, the classification of cities is one of the important methods in the science of economic geography, the classification of cities in relation to any character or combination of them is understood. The most common classification of urban population punk classification is as follows: by size (number and density of population); function (function)symbols; participation in territorial labor distribution; origin; and, finally, IgJ .

It is possible to configure that different criteria are adopted, depending on the quantitative indicators of the number of inhabitants in the countries of the world. For example, it is noted that the minimum indicator is given in the Uganda state - the status of a city with a population of more than 100 people (at the same time, talabi is also put to be an administrative or commercial center). A similar situation is observed in countries where some of the population is considered sparse (in Greenland and Iceland more than 200 people are given urban status to the population puntks). As a state with the maximum criteria, Japan can be cited as an example. According to the legislation of this country, the population should be more than 50 thousand people, at the same time $60 \%$ of the population (taking into account household) is required to work in the non-agrarian sector .

\section{ANALYTICAL BACKGROUND}

In the National Legislative System, the quantitative criterion for the number of inhabitants is also adopted. At present, the normative acts of the Republic of Uzbekistan in this regard are in the process of evolution. In particular, in the new edition of the "urban code of the Republic of Uzbekistan", which has been in the process of discussion in the style of the project since 2019 (June 2019), if the 2 article of the "urban code" adopted in 2002 did not comment on the concept of "main concepts"City, this gap is being overcome. In it, the following option is proposed: quot ;City -... As part of the administrative-territorial structure of the Republic of Uzbekistan, the buildings and structures of residential buildings, social, production, transport, engineering and other purposes are densely located, as well as have a specific economic, historical, scientific and cultural significance, the main part of the population is occupied by industrial enterprises, public administration structures, institutions of general secondary and higher education, science and culture, $" \uparrow$.

The main thing is that in the current code the concept of "city parcel" was not even explained. In fact, on March 13, 2009, the Cabinet of Ministers of the Republic of Uzbekistan issued the 68th resolution "on additional measures to improve the administrative-territorial structure of the population punches of the Republic of Uzbekistan", according to which the ranks of urban settlements in the Republic increased several times, 965 large rural population punches were given the status of urban

The draft law in the new edition is also planned to end this issue. According to it, the city is a settlement, " defined by the legislation of the Republic of Uzbekistan as an administrative-territorial structure of the Republic of Uzbekistan, the name, status and boundaries of which are part of the residential buildings, buildings and structures of social, production, transport, education, engineering and other purposes are located, as well as of specific industrial or scientific significance, the, the territory occupied by scientific and public administration institutions and the number of which exceeds two thousand people (Industrial, resort, scientific, railway hoaxes, fisheries, mining, settlements) in proportion to the area that serves as the administrative center of districts or where the main part of the population is occupied, is said to be".

In Article 9 of the town-planning code, the printouts of the division of population punches of the Republic are indicated, including cities, the following quantitative order of urban settlements is noted : the largest population punches - the number of population consists of more than 1 million people; the largest population punches - from 250 thousand to 1 million; the largest population punches - from 100 thousand to

In fact, in the practice of many countries, that is, in the classification of cities, the second category is defined as population punks - the amount of the population from 500 thousand to 1 million. In Uzbekistan, cities with a population of 500 thousand and more are not majors due to the situation (unless in the coming years Samarkand and Namangan are expected to be included in the list of these cities). This situation raises a number of problems related to the modernization of territories and the limitation of the possibility of attracting labor resource migration.

According to the language of specialists, Uzbekistan is a country with a single large megacities, as well as a large number of small towns, with a population of not more than 500 thousand people . Zarafshan economic district is no exception.

\footnotetext{
† Ўзбекистон Республикасининг Қонуни. Ўзбекистон Республикасининг Шахарсозлик Кодекси (янги тахрир). ID-2887. (Лойиха) // https://regulation.gov.uz/oz/document/2887
} 
Another important change proposed to the National Legislative System in the issue of urban planning is the classification of these urban parcels. In the proposed amendment to the above - mentioned draft law, it is noted that, depending on the population, urban settlements can be divided into : large population punk the population of which is more than 7 thousand people; large population punk - from 5 thousand to 7 thousand people; average population punk - from 3 thousand to 5 thousand people; small population punk-from 2 thousand to

Speaking of the problem of cities, first of all, it is necessary to touch separately on the concept of" urbanization". As noted by direct specialists, urbanization (visual impairment) is the most common cause of visual impairment. urbanization, lot. urbanus is a city, urbs is a city) - this is an understanding of the growth of cities, the population in which they live, the increase in the proportion of the population of the city in the general population, the formation and development of the urban system . At the same time, urbanization is a historical process that provokes the unification of population groups by increasing the role of cities in the life of this society, creating changes in the employment, lifestyle and culture of society.

Urbanization as a global reality, its projection depends on a certain historical and davriy phenomenon, and there are differences between continental, interstate and interregional. Representatives of the Mainstream link the process of formation of urbanization with a new era (the development of capitalism). In general, they distinguish the following sequence of its manifestations from the point of view of time and space: outlandish Europe-North America - Australia - Eastern Europe - Latin America - Asia Africa .

\section{DISCUSSIONS}

Historically, it is difficult to agree on this idea. Because exactly at the end of the list are the continents Asia (Messopatamia, India, China) and Africa (CAD. Egypt) in the history of mankind, it would be logical for it to be considered the cradle of urban culture formation and urbanization processes and stand at the beginning of the list. Modern trends of urbanization are becoming more controversial. In particular, while there has been growth in developing countries for many years, quantitative indicators in developing countries are also noted to be stagnating or declining. Between some countries located in one region, and even in different regions of one country, uneven urbanization of content and quantitatively is noted. Uzbekistan is an example of this.

Just as all spheres and sectors of social life have their own evolution, urbanization has gone through several stages during the course of evolutionary development. In this regard, the theoretical views of the American scientist Djek Djibs (although mainly devoted to the analysis of modern urbanization processes) play an important scientific role. The Dj.Djibs divided the five stages of urbanization under the influence of population positioning and demographic processes :

One of them. The position of the cities is low, in growth it lags behind the villages ("preurbanization"); 2. cities begin to grow faster than in the village, population growth in the village slows down (initial urbanization); 3. As a result of the outbreaks of migration to the city, population depopulation is observed in the villages (classical urbanization); 4. Large cities reach apogee in growth, villages and after them small towns lose their population (stshnggi urbanization); 5. The growth of population punks of different sizes (urban and rural) stabilizes the population beyond the city, the flow of small towns and villages kuchayad (counter-urbanization).

These are a number of components (components)of modern urbanization, which are divided into economic, social, demographic, technical, cultural, information, etc. Proceeding from the research objectives, we believe that the main focus is on the economic, social and demographic component as a priority. If the economic component of urbanization is expressed in the concentration of production - in the territorial and sectoral spheres, in the application of high technologies, in the division of labor, in the changes in the structure of the network of the economy, the consequences of the social component are reflected in changes in the way of living and conditions, in the growth and The demographic consequences of urbanization are manifested in the accumulation of the population in cities (migration), in employment, in the reduction of births from the cost of living, in the growth of the average standard of living.

The above-mentioned components of urbanization also serve as its cause. The main thing in them is this economy. The economic causes of urbanization are the growth of productive forces, the formation and development of industry, the downturn of enterprises, the regional and network concentration of production, etc., which, under the influence of industrial enterprises, lead to the accumulation of the population around them and the influx of migration to them. In addition, the development of social infrastructure in cities attracts the population of education, health care system, favorable communal conditions, etc.

In the conditions of the formation of the current market economy, there are conflicting situations in modern urbanization processes in Uzbekistan, and more precisely, during the first decades of 
independence, the deurbanization process was observed more and more. This situation was analyzed and criticized at the government level and appropriate conclusions were drawn.

In particular, in 2019, the president of the Republic of Uzbekistan Sh.M.Within the framework of the structural reforms carried out in the country in the decree "on measures for the radical improvement of urbanization processes"adopted by Mirziyoyev "as a factor leading to the growth and sustainable development of the well-being of the population of cities, along with the implementation of major strategic investment projects, the urbanization process was not taken into Despite the measures taken to turn large rural population punks into urban settlements, today's urbanization rate does not meet the modern requirements for the development of urban areas and remains significantly above world trends. Bunda noted that the level of urbanization does not yet have a stable feature. There is also an opinion that in 2009-2018 in the Republic there is a downward trend in the level of urbanization, while the number of urban population increased from only 1065 to 1071 .

It is known that Uzbekistan has problems of different socio-geographical and population placement. Taking into account the peculiarities of Bukhara, Navoi and Samarkand regions, which include Zarafshan economic Rayon, industrial cities are distinguished by their genetic, functional and typological features.

\section{RESULTS}

This feature is primarily associated with the development of resource cities. The specific sociogeographic and demographic conditions of the resource city addresses, as well as their role and location in the state city network determine the problems and landscape in their development and determine the modern system of population placement in the Republic as a member of Mukhim. This situation has led to the selection of resource cities of Uzbekistan as well as resource urban settlements as research areas as a reserve in the urban sectors of the state.

International experience testifies that resource-intensive urban settlements are created and developed on the basis of the availability of Natural Resources. Economists and geographers began to actively study the development of economic, social, geographical and demographic aspects of resource urban settlements in the second half of the 60-ies of the XX century. As a result of scientific and technical progress and increased demand for untapped mining-rich areas in Canada, Austria, the north of America, the Urals and the Urals, as well as Central Asia, many urban settlements emerged as a result of the processing of Natural Resources. The further fate of these urban settlements directly depended on the pace of extraction of these resources. Such urban settlements began to play an important role in the people's economy of these states .

For the first time the terms" resource City"," resource address " are used by the famous Russian scientist L.N.Y. Karpov is mentioned in the book" Novie Rayon v economy razvitix kapitalisticheskix stran " (new Rayons in the economy of developed capitalist countries). This book examines the organization of resource cities and settlements in Canada, Alaska, Australia and Northern Scandinavia and the international experience of solving socio-economic problems in their development . L.N.Y. In the theoretical and practical study of non-Karpov resource cities A.A. Mines, D.A. Ganechko, I.V. Kamar, E.H. Persik and other scientists also made their contributions .

In the system of locating the population of independent states, the role and location of resource cities and urban settlements Komplex analysis and forecasting the possibility of their development over a long period of time is methodologically important. This situation is mainly acute at the moment when the underground and all natural resources of the Republic are actively involved in the economic process.

The attached analysis of the organization and development of resource cities, which are inextricably linked with the whole region with a specific demographic status, as well as the cities of the currently under study, is of great importance for the Republic of Uzbekistan. This makes it possible to select the directions of further development of cities with scientifically based data.

Determination of the features of the organization of resource - intensive urban settlements and their networks is the main condition for studying the problems of the history of urbanization as well as their various territorial levels in a complex way.

It should be noted that, on the example of Central Asia, the problem of the development of cities was the first one of the specialists of our homeland.S.Soliev made an analysis . In his work, the problems of the emergence and development of cities have been seen. His work can serve as a methodological basis in the analysis of the occurrence of a network of cities with resources of the territory and other types.

The establishment of a network of resource cities is the result of a long-term historical process associated with socio-economic factors during the development of society, as well as the use of Natural Resources in economic activity.

\section{CONCLUSIONS}

The organization of cities, including resource cities, is a process connected with the movement of urbanization forces based on the territorial division of Labor. Although resource-intensive settlements are an integral part of the population punk system, unlike other cities, they are characterized by dependence 
on natural conditions and the use of resources in mining. At the same time, the emergence, modern structure and development of this population is determined by the availability of natural conditions and resources, the size of their reserves, extraction, quality and application.

Thus, it can be said that modern historical research is actively integrated into science research methods. This innovation method implies the widespread use of practical results in the Humanities, Social, exact and Natural Sciences. In this regard, in the study of the history of cities, first of all, the science of geography, as well as the achievements of Economic Sciences, the introduction of methodological equivalents further deepen the scientific results obtained from the research. Importantly, this method not only provides for the past and present tasvirini, but also allows to predict the future on a scientific basis, based on accurate calculations.

\section{REFERENCES}

1. Socio-economic geography: concepts and terms. The dictionary-directory / under the editorship of A. P. Gorkina. Smolensk: Oikumena, 2013. Pp. 73.

2. Socio-economic geography: concepts and terms. The dictionary-directory / under the editorship of A. P. Gorkina. Smolensk: Oikumena, 2013. Pp. 73.

3. Lappo G. M. Geography of cities: Studies. A Handbook for geography. F-tov universities. M., 1997. Pp. 39-40.

4. Lappo G. M. Geography of cities: Studies. A Handbook for geography. F-tov universities. M., 1997. Pp. 40-41.

5. Classification of cities // http://edu.tsu.ru/eor/resourse/174/html/39.html

6. Uzbekiston Respublikasining OnOne. Uzbekiston Respublikasining Searsolin Code (Yangi tarir). ID-2887. (Louie) // https://regulation.gov.uz/oz/document/2887

7. http://www.lex.uz/acts/1486944

8. Urbanization and industrialization in Uzbekistan: challenges, problems and prospects. CER. Policy brief 2009/01. Tashkent, 2009. Pp. 16.

9. Socio-economic geography: concepts and terms. The dictionary-directory / under the editorship of A. P. Gorkina. Smolensk: Oikumena, 2013. Pp. 281-282. 